\title{
BMJ Global Heatth Building resilient health systems in Africa beyond the COVID-19 pandemic response
}

\author{
Akalewold T Gebremeskel, ${ }^{1}$ Akaninyene Otu, ${ }^{2,3}$ Seye Abimbola (1) ,4 \\ Sanni Yaya (1) ${ }^{1,5}$
}

\begin{abstract}
To cite: Gebremeskel AT, Otu A, Abimbola S, et al. Building resilient health systems in Africa beyond the COVID-19 pandemic response. BMJ Global Health 2021;6:e006108. doi:10.1136/ bmjgh-2021-006108
\end{abstract}

Handling editor Valery Ridde

Received 25 April 2021 Accepted 2 June 2021

Check for updates

(c) Author(s) (or their employer(s)) 2021. Re-use permitted under CC BY-NC. No commercial re-use. See rights and permissions. Published by BMJ.

${ }^{1}$ School of International Development and Global Studies, University of Ottawa, Ottawa, Ontario, Canada ${ }^{2}$ Department of Infection and Travel Medicine, Leeds Teaching Hospitals NHS Trust, Leeds, UK ${ }^{3}$ Department of Internal Medicine, College of Medical Sciences, University of Calabar, Calabar, Nigeria

${ }^{4}$ School of Public Health, University of Sydney, Sydney, New South Wales, Australia

${ }^{5}$ The George Institute for Global Health, Imperial College London, London, UK

Correspondence to

Dr Sanni Yaya;

sanni.yaya@uottawa.ca

\section{INTRODUCTION}

Since the outbreak of the COVID-19 pandemic in December 2019 in China, health systems across the globe have struggled to contend with unprecedented shocks arising from this novel disease. Health systems in Africa are attracting more attention than before as these fragile systems have previously struggled to respond to the effects of health emergencies and pandemics. ${ }^{1}$ After the 2014 Ebola outbreak in parts of Africa, governments were encouraged by the WHO to improve the resilience of their health systems. ${ }^{2}$ This led to advocacy for a clear and concise definition of health system resilience. ${ }^{23}$ Fragility is the insufficient capacity of the state, system and/ or communities to manage, absorb or mitigate risks. ${ }^{4}$ Resilience is what happens when a health system adapts to shocks or stress in a context of robustness. ${ }^{5}$

Health system resilience has been defined as the ability of health actors, institutions and populations to demonstrate absorptive, adaptive, accessible and transformative capacities to prepare for and effectively respond to health system shocks and disturbances. ${ }^{6}$ Health system resilience is directly linked to health system governance ${ }^{7}$ - that is, resilience depends on the choices of groups and individuals as they make, change, monitor and enforce the rules (formal and informal) that govern the health system. ${ }^{8}$ The COVID-19 pandemic has laid bare the longstanding structural drivers of health inequities. There are concerns that public health policy could exacerbate the deleterious effects of these inequities if deliberate efforts are not made to factor these social vulnerabilities into public health practices and health system governance.

Egypt was the first African country to report COVID-19 on 14 February 2020. As of 31 May 2021, there have been 170002963 confirmed
COVID-19 cases, 3539381 confirmed deaths and 1546316352 vaccine doses administered ${ }^{9}$ On 17 April 2020, the WHO stated that Africa could be the next COVID-19 epicentre. But available data so far do not reflect the projected impact of this novel disease on the region. ${ }^{10}$ Health systems across Africa are not new to dealing with deadly infectious disease outbreaks. West African countries such as Guinea, Liberia, Nigeria and Sierra Leone were faced with an Ebola epidemic from 2014 to $2016 .{ }^{11}$ Insights obtained from dealing with the epidemic might have strengthened those health systems somewhat as these disease outbreaks also put a considerable strain on their health systems in the process. ${ }^{12}$ However, resilience requires robustness. While some health systems have demonstrated features of adaptiveness in responding to a new challenge, such adaptiveness can only go so far in the context of weak, fragile and non-robust health systems.

The additional burden of dealing with COVID-19 is taking its toll on already fragile health systems. Ensuring adequate supply of protective equipment, laboratory testing, therapeutics, mechanical ventilators, isolation of confirmed or suspected cases, contact tracing and treatment for severe illness, and just dealing with the sheer number of COVID-19 cases have been daunting in Africa, and even in places with much better infrastructure. ${ }^{13-16}$ The situation is exacerbated by limited health services in rural compared with urban areas. ${ }^{17}$ This is occurring in a region that is struggling to implement vital infection control measures such as frequent handwashing, lockdowns and social distancing strategies aimed at slowing the spread of SARS-CoV-2. ${ }^{18}$

Many countries in Africa have lean health financing and infrastructure development. With $25 \%$ of the global disease burden, sub-Saharan Africa has 3\% of the world's 
health manpower. ${ }^{19}$ One in three Africans—422 million people-are estimated to earn below $\$ 1$ a day ${ }^{20}$ in rural areas. Weak health systems response to the COVID-19 pandemic could easily precipitate a monumental socioeconomic crisis. ${ }^{21}$ There is a clear and present need to improve the resilience of health systems across Africa. It is an inevitably daunting task (given variations across the continent) which WHO has been at the forefront of championing. ${ }^{22} 23$

Understanding the resilience of health systems to COVID-19 calls for cross-country (within Africa and beyond) comparative analyses of the technical ${ }^{4}$ and political response to the pandemic. ${ }^{24}$ In this article,we highlight four health system challenges to controlling COVID-19, and offer potential strategies to address them, considering the nuances of the systems across Africa and their widely varying current level of resilience. ${ }^{25}$

\section{COMMUNITY AND COMMUNITY HEALTH WORKER ENGAGEMENT}

Community engagement plays role in resilience, and community health workers serve as a bridge between communities and health systems, ${ }^{26}$ but are only $3 \%$ of the world's health manpower. ${ }^{19}$ This gap has been magnified by the COVID-19 pandemic with limited community engagement in health planning and delivery, poor risk communication and advocacy. The population density of community health workers varies across Africa, from 0.5 to 1 per 1000 people. Community health workers are organised in very different ways across various African countries. In many countries, they receive narrowly focused training, are largely underpaid, are under-utilised and are poorly integrated in health systems in the region. ${ }^{27}$ These deficiencies are likely to have impacted negatively on the COVID-19 response at the community level.

Most public health measures to control COVID-19 are required to be implemented at community level, and so community health workers are playing a pivotal role in fighting the COVID-19 pandemic, especially in weak health systems. ${ }^{27}$ However, pre-existing shortage of community health workers is affecting their capacity to respond to COVID-19, a pandemic that has revealed that community health workers are equally exposed to infections and mental health related risks with the later tending to be under-recognised and poorly managed. ${ }^{28}$ Barriers to community engagement with health include limited logistic supply, fragmentation of services, poor coordination and competing non-governmental organisations. ${ }^{29}$

To build resilient health systems, securing community buy-in is vital. Priority should be given to addressing social determinants of health as critical components for achieving universal health coverage.$^{30}{ }^{31}$ In South Africa, for example, the unique challenges of the COVID-19 pandemic changed the way community organisations worked for the better. Organisations that worked in silos during other emergencies had to pool their expertise and resources to form collaborative networks, with positive results. ${ }^{32}$ In Tanzania, a combination of financial and non-financial incentives was shown to be effective in boosting the motivation and satisfaction of health workers. ${ }^{33}$ The provision of non-financial incentives, such as community recognition, acquisition of knowledge and skills as well as personal development, appear to be low-hanging fruits that could be harnessed even in lowresource settings. There is a need to adjust the training of community health workers to produce broadly proficient community workers who can address multiple health problems.

Mottos like 'universal health coverage' and 'no one left behind' cannot be achieved without training and deploying more community health workers. These health workers will require infection prevention training and improved access to physical and mental health services. ${ }^{28}$ They will need to be supported by the establishment of more rapid resource flow channels and integrating technology to create robust health information systems. ${ }^{34}$ Improving job satisfaction among health workers is crucial and this is likely to be achieved by providing both professional and financial incentives. ${ }^{29}$ Advocacy will be required at several levels to promote respect and protect the community health role within the formal health system. $^{34}$

\section{MEDICAL AND DIAGNOSTIC SUPPLIES}

Lack of investment in medical and diagnostic supplies has made it harder for African nations to effectively respond to COVID-19 along with other health issues such as the HIV/AIDS pandemic and maternal and child health. Early on in the COVID-19 pandemic, there were reports of lack of personal protective equipment, shortage of intensive care units and ventilators in Egypt, Kenya, South Africa and Zimbabwe. ${ }^{35}$ All African countries are net importers of medical and pharmaceutical products, with Africa importing 94\% of its pharmaceuticals in total ${ }^{36}$ Local manufacturers produce $25 \%-30 \%$ of pharmaceuticals and less than $10 \%$ of medical supplies that are on the African market. ${ }^{37}$ In addition, largely government-led, the health product supply chains in the region appear to be inflexible for forecasting, procuring, storing, distributing and monitoring essential medicines and medical supplies. ${ }^{38}$

Many African countries lack a national regulation system for medical products, including for medicines (drugs), vaccines, blood products, diagnostics and medical devices, which are critically important for healthcare delivery. Notably, there is evidence of shortage of medicines and supplies compared with demand leading to inefficient and low quality of healthcare and low quality of medicines especially in a poorly regulated environment. ${ }^{39}$ Lack of medicines or point-of-care diagnostic testing kits result in referrals to other facilities, thereby creating access issues among disadvantaged populations. Furthermore, the patients are exposed to long waiting 
times, poor infection control practices, extra costs, unsafe and low-quality healthcare.

During the current COVID-19 pandemic, intra-country supply chains within many African countries appear to have been affected in the same way as extra-continental supply chains. COVID-19 has affected passenger and cargo transport with direct impacts on supply chains within the region. The border closures have also slowed and even halted the flow of goods in many countries. This pandemic has effectively exposed the vulnerability of the African health systems that is created by this overdependence on imports for pharmaceutical and medical supplies.

Ensuring availability of medical and diagnostic supplies will require addressing key dimensions of access such as availability and affordability. In many African countries, the government is solely responsible for providing medical and logistic supplies in the face of competing demands on scarce resources. There is a need to create collaborations between governments, pharmaceutical companies and developers of diagnostic equipment to circumvent some of the constraints relating to supply chain, prices and procurement processes. In addition, robust and effective regulatory systems are needed to guarantee the quality, safety and efficacy of medical products while promoting regional and trade and socioeconomic advancement.

\section{DATA GOVERNANCE AND STEWARDSHIP}

Reliable health data can transform health systems by guiding policy decision and catalysing timely responses. Despite improvements in data quantity, the coverage, quality, frequency and capacity to use and manage health sector data have been limited in the region. The general availability of data on health outcomes is low at $28.9 \% .{ }^{40}$ Hence, reliable data on COVID-19 trends have been scarce and many governments in the region have been forced to make policy decisions 'in the dark'. ${ }^{41-43}$ In 1998, the WHO introduced a strategy to detect, report and effectively respond to priority diseases, and to integrate multiple existing vertical surveillance systems and linking laboratory and other data sources for public health action. ${ }^{44}$

However, the challenges of health data generation, transmission, analyses, dissemination and utilisation for action in the region have persisted. Given the pivotal nature of this resource, the African Union has been promoting technology-assisted disease surveillance two times per day to improve COVID-19 prevention, diagnosis, treatment and control among member states. ${ }^{45}$ There are debates as to whether digital health technology solutions are appropriate in rural African settings, where infrastructure such as electricity, mobile telephony and internet connectivity are lacking. Finding sustainable and cost-effective ways to mitigate these drawbacks should be the focus. The utility of paper-based data is clearly limited in the today's fast-paced world.
Actors in a health system, like any other business enterprise, need data to effectively respond to health system challenges and track progress. Enhanced data stewardship and data governance systems are required across Africa. The Protection of Personal InformationAct (POPI) Act which provides specific legislation for health data in South Africa is one example of such a data governance system. ${ }^{46}$ Data stewardship/management refers to the systematic process of data collection, sharing and analysis. Data governance addresses policy setting, organisation and establishment of accountability frameworks with respect to health data. A governance model that protects data without impeding access to population health data is required. Coordinated efforts are needed to strengthen evidence-based practice while generating robust evidence to guide timely response and promote better health outcomes. ${ }^{47}$

Health systems need training, supply of technology and transfer from paper-based to electronic data collection systems. The last two decades have witnessed the rise of mobile health, incorporating mobile phones, tablets and other wireless devices into heath programmes. ${ }^{48}$ This high mobile phone penetration in Africa ${ }^{49}$ can be leveraged to organise training and disseminate vital information for tracking, monitoring and addressing emerging needs in disease outbreak situations. During the Ebola outbreaks in West Africa in 2014-2016, mobile phone data were used to model travel patterns, and hand-held sequencing devices permitted more effective contact tracing and a better understanding of outbreak dynamics. ${ }^{50}$

\section{HEALTH INFRASTRUCTURE DEVELOPMENT}

The amount spent on health has been abysmally low, especially in sub-Saharan Africa, and the poor level of health infrastructure in countries such as Tanzania, Zimbabwe, Kenya and Nigeria has been linked to lack of long-term investment in health. ${ }^{51}$ Hence, there is less health infrastructure development with a plethora of under-funded public health facilities in the region. There are deepseated challenges posed by poor construction and lack of appropriate technology which are compounded by wrong siting/location of key health infrastructure due to political considerations. Health infrastructure development in many African countries is controlled by governments. It is hard for public organisations and governments alone to respond sufficiently. This makes a case for diversifying responsibility among key players and establishing partnerships with private (including non-profit) actors within and across countries in the region.

While many are clearly struggling to achieve universal health coverage, budget allocations for health infrastructure increased in 48 sub-Saharan African countries between 2000 and 2015. This increase has been linked to a reduction in maternal mortality and morbidity by almost a quarter. ${ }^{52}$ Life expectancy among mothers also increased by 4 years. ${ }^{52}$ But the COVID-19 pandemic has revealed some weaknesses: a shortage of intensive care 
units, ventilators and personal protective equipment with the capacity of many health facilities to cope with the large numbers of patients with COVID-19 and infections among health workers. ${ }^{35}$ In April 2020, WHO reported that there were just 2000 ventilators across 41 sub-Saharan African countries and 5000 intensive care beds across 43 sub-Saharan African countries.

Health infrastructure development is required to facilitate the seven domains of quality ${ }^{53}$ - patient experience, effectiveness, efficiency, timeliness, safety, equity and sustainability. A robust engagement with the private sector in health system financing and administration could potentially address some infrastructural limitations. This could be achieved by carefully regulated public private partnership to promote resource sharing, collaboration, competitiveness and economies of scale, especially in countries with strong public finance management and regulatory capacity. ${ }^{54}$ The private sector can contribute to the delivery of assets, technology, services, capital, for healthcare infrastructure development and operations. ${ }^{55}$ However, public private partnership requires that governments have the necessary regulatory capacity to ensure that the drawbacks of neoliberal policies are curtailed. ${ }^{56}$ They are not advisable otherwise.

So far, the contribution of public private partnerships to health service delivery and financing have been seen in some African countries. ${ }^{57}$ However, these contributions are minimal in pharmaceuticals, digital health technology, quality assurance, diagnostic, laboratory and professional training. ${ }^{52}$ More efforts and regulatory attention are required to fill gaps in the existing public private partnership frameworks. Majority of Africans live in rural areas and obtain their livelihood within informal sector; many are unable to pay for healthcare from their pocket or payrolls. Data from many African countries suggest that in a context of high informality of labour markets, tax-financed national health systems is a particularly viable mechanism for mobilising resources for the health sector. ${ }^{58}$ It is also important to scale up collaboration with local and international civil society organisation for resource mobilisation while harmonising these efforts with local context and priority.

\section{CONCLUSION}

The COVID-19 pandemic has further exposed the fragility of the health systems in sub-Saharan Africa and the need to boost the resilience of these systems to respond to disease outbreaks. Priority should be given to community-led health initiatives and health workers; ensuring reliable medical and diagnostic supplies; fostering evidencebased practice; and raising additional revenue to boost health system financing within the region, including for health infrastructure development. These recommendations are largely focused on boosting health system resilience at the community level. However, they all require stronger health system governance, including multisectoral collaboration within countries. In addition, greater regional collaborations on these fronts could secure lasting gains for African health systems that extend beyond the current pandemic.

Twitter Seye Abimbola @seyeabimbola

Contributors SY led the design and the review. ATG developed the initial draft. SY, SA and AO provided feedback and critically reviewed the manuscript for its intellectual content. SY had final responsibility to submit. All authors read and approved this final commentary.

Funding The authors have not declared a specific grant for this research from any funding agency in the public, commercial or not-for-profit sectors.

Competing interests SY and SA are, respectively, associate editor and editor-inchief of BMJ Global Health.

Patient consent for publication Not required.

Provenance and peer review Not commissioned; internally peer reviewed. Data availability statement No data are available.

Open access This is an open access article distributed in accordance with the Creative Commons Attribution Non Commercial (CC BY-NC 4.0) license, which permits others to distribute, remix, adapt, build upon this work non-commercially, and license their derivative works on different terms, provided the original work is properly cited, appropriate credit is given, any changes made indicated, and the use is non-commercial. See: http://creativecommons.org/licenses/by-nc/4.0/.

\section{ORCID iDs}

Seye Abimbola http://orcid.org/0000-0003-1294-3850

Sanni Yaya http://orcid.org/0000-0002-4876-6043

\section{REFERENCES}

1 United Nation. MDG 2015 rev (July 1).pdf [Internet]. Available: https://www.un.org/millenniumgoals/2015 MDG_Report/pdf/MDG\% $202015 \% 20$ rev\%20(July\%201).pdf [Accessed 26 Jun 2020].

2 Turenne CP, Gautier L, Degroote S, et al. Conceptual analysis of health systems resilience: a scoping review. Soc Sci Med 2019;232:168-80.

3 Bozorgmehr K, Roberts B, Razum O, eds. Health Policy and Systems Responses to Forced Migration [Internet]. Springer International Publishing, 2020. https://www.springer.com/gp/book/ 9783030338114

4 Organisation for Economic Co-operation and Development. States of fragility 2016: understanding violence [Internet]. Available: https:// www.oecd-ilibrary.org/development/states-of-fragility-2016 9789264267213-en;jsessionid=Gn-dB_JUwaszmMF70NL2X̄kWJ.ip10-240-5-5 [Accessed 09 Jan 2021].

5 Abimbola S, Topp SM. Adaptation with robustness: the case for clarity on the use of 'resilience' in health systems and global health. BMJ Glob Health 2018;3:e000758.

6 Organisation for Economic Co-operation and Development. Guidelines for Resilience Systems Analysis: Facilitation Guide [Internet]. (Best Practices in Development Co-operation), 2014. Available: https://www.oecd-ilibrary.org/development/guidelinesfor-resilience-systems-analysis-facilitation-guide a0714975-en [Accessed 31 May 2021].

7 Topp SM. Power and politics: the case for linking resilience to health system governance. BMJ Glob Health 2020;5:e002891.

8 Abimbola S, Negin J, Martiniuk AL, et al. Institutional analysis of health system governance. Health Policy Plan 2017;32:1337-44.

9 World Health Organization. Coronavirus Disease (COVID-19) Dashboard [Internet]. Available: https://covid19.who.int [Accessed 21 Nov 2020].

10 World Health Organization. Coronavirus (COVID-19) events as they happen [Internet]. Available: https://www.who.int/emergencies/ diseases/novel-coronavirus-2019/events-as-they-happen [Accessed 31 May 2021].

11 Bell BP. Overview, Control Strategies, and Lessons Learned in the CDC Response to the 2014-2016 Ebola Epidemic. MMWR Suppl [Internet], 2016. Available: https://www.cdc.gov/mmwr/volumes/65/ su/su6503a2.htm [Accessed 31 May 2021]

12 Organisation for Economic Co-operation and Development. Strengthening health systems during a pandemic: The role of development finance [Internet], 2014. Available: https://www.oecd. org/coronavirus/policy-responses/strengthening-health-systems- 
during-a-pandemic-the-role-of-development-finance-f762bf1c/ [Accessed 31 May 2021].

13 Charlesworth A. Shock to the system: COVID-19's long-term impact on the NHS [Internet]. The Health Foundation. Available: https:// www.health.org.uk/news-and-comment/blogs/shock-to-the-systemcovid-19s-long-term-impact-on-the-nhs [Accessed 27 Oct 2020].

14 Nepomnyashchiy L, Dahn B, Saykpah R, et al. COVID-19: Africa needs unprecedented attention to strengthen community health systems. Lancet 2020;396:150-2.

15 UNICEF. COVID-19 impact assessment and outlook on personal protective equipment [Internet]. Available: https://www.unicef.org/ supply/stories/covid-19-impact-assessment-and-outlook-personalprotective-equipment [Accessed 02 May 2020].

16 World Health Organization. Shortage of personal protective equipment endangering health workers worldwide [Internet]. Available: https://www.who.int/news-room/detail/03-03-2020shortage-of-personal-protective-equipment-endangering-healthworkers-worldwide [Accessed cited 2020 May 2].

17 Mbunge E. Effects of COVID-19 in South African health system and society: an explanatory study. Diabetes Metab Syndr 2020;14:1809-14.

18 Otu A, Ebenso B, Labonte R, et al. Tackling COVID-19: can the African continent play the long game? J Glob Health 2020;10:010339.

19 World Health Organization. The World Health Report 2006 - working together for health [Internet]. Available: https://www.who.int/whr/ 2006/en/ [Accessed 31 May 2021].

20 Hofer KH Baldwin Tong, and Martin. Poverty in Africa is now falling - but not fast enough [Internet]. Brookings 2019 https://www. brookings.edu/blog/future-development/2019/03/28/poverty-inafrica-is-now-falling-but-not-fast-enough/

21 World Bank. COVID-19 (Coronavirus) Drives Sub-Saharan Africa Toward First Recession in 25 Years [Internet]. World Bank. Available: https://www.worldbank.org/en/news/press-release/2020/04/09/ covid-19-coronavirus-drives-sub-saharan-africa-toward-firstrecession-in-25-years [Accessed 02 May 2020].

22 UNICEF Canada : For Every Child. WHO and UNICEF to partner on pandemic response through COVID-19 Solidarity Response Fund [Internet]. Available: https://www.unicef.ca/en/press-release/whoand-unicef-partner-pandemic-response-through-covid-19-solidarityresponse-fund [Accessed 02 May 2020].

23 African Union. Africa Health Strategy 2016 - 2030 | African Union [Internet]. Available: https://au.int/en/documents/30357/africahealth-strategy-2016-2030 [Accessed 31 May 2021].

24 Greer SL, King EJ, da Fonseca EM, et al. The comparative politics of COVID-19: the need to understand government responses. Glob Public Health 2020;15:1413-6.

25 Karamagi HC, Tumusiime P, Titi-Ofei R, et al. Towards universal health coverage in the WHO African region: assessing health system functionality, incorporating lessons from COVID-19. BMJ Glob Health 2021;6.

26 Kamal-Yanni M. Never again: building resilient health systems and learning from the Ebola crisis; 12 .

27 Ballard M, Bancroft E, Nesbit J, et al. Prioritising the role of community health workers in the COVID-19 response. BMJ Glob Health 2020;5:e002550.

28 Chang D, Xu H, Rebaza A, et al. Protecting health-care workers from subclinical coronavirus infection. Lancet Respir Med 2020;8:e13.

29 USAID. under-recognized-cadres-overview.pdf [Internet]. Available: https://www.capacityplus.org/files/resources/under-recognizedcadres-overview.pdf [Accessed 31 May 2021]

30 World Health Organization. A conceptual framework for action on the social determinants of health: debates, policy \& practice, case studies. [Internet], 2010. Available: http://apps.who.int/iris/bitstream/ 10665/44489/1/9789241500852_eng.pdf [Accessed cited 2021 May 31].

31 Elston JWT, Cartwright C, Ndumbi P, et al. The health impact of the 2014-15 Ebola outbreak. Public Health 2017;143:60-70.

32 Colvin CJ, van PM. How COVID-19 changed community engagement in South Africa's low income areas [Internet]. Available: https://theconversation.com/how-covid-19-changed-communityengagement-in-south-africas-low-income-areas-146767 [Accessed 31 May 2021].

33 Mpembeni RNM, Bhatnagar A, LeFevre A, et al. Motivation and satisfaction among community health workers in Morogoro region, Tanzania: nuanced needs and varied ambitions. Hum Resour Health 2015;13:44.

34 Lehmann U, Twum-Danso NAY, Nyoni J. Towards universal health coverage: what are the system requirements for effective largescale community health worker programmes? BMJ Glob Health 2019;4:e001046.
35 Wadvalla B-A. How Africa has tackled covid-19. BMJ 2020;370:m2830.

36 United Nations Economic Commission for Africa. Insights on African businesses' reactions and outlook to COVID-19, 2020. Available: https://repository.uneca.org/handle/10855/43780 [Accessed 31 May 2021].

37 Banga et al. Africa trade and Covid-19.pdf [Internet]. Available: https://www.odi.org/sites/odi.org.uk/files/resource-documents/ africa_trade-covid-19_web_1.pdf [Accessed 21 Nov 2020].

38 Yadav P. Health product supply chains in developing countries: diagnosis of the root causes of Underperformance and an agenda for reform. Health Syst Reform 2015;1:142-54.

39 Gergen J, Crigler L, Perry H. CHW ReferenceGuide sm.pdf [Internet]. Available: https://www.mchip.net/sites/default/files/ mchipfiles/CHW_ReferenceGuide_sm.pdf [Accessed 25 Jun 2020].

40 The Africa Report.com. Africa needs more health data to improve response to health crises [Internet], 2020. Available: https://www. theafricareport.com/25951/lack-of-statistical-capacity-means-africarisks-shooting-in-the-dark-on-coronavirus/ [Accessed 07 Jan 2021].

41 USAID. Africa needs more health data to improve response to health crises [Internet]. The Africa Report.com, 2020. Available: https:// www.theafricareport.com/25951/lack-of-statistical-capacity-meansafrica-risks-shooting-in-the-dark-on-coronavirus/ [Accessed 31 May 2021].

42 Anema A, Kluberg S, Wilson K, et al. Digital surveillance for enhanced detection and response to outbreaks. Lancet Infect Dis 2014;14:1035-7.

43 The Economist [internet]. The Economist. lacking data, many African governments make policy in the dark, 2020. Available: https://www. economist.com/middle-east-and-africa/2020/05/07/lacking-datamany-african-governments-make-policy-in-the-dark [Accessed 31 May 2021].

44 Ahmed K, Bukhari MA, Mlanda T, et al. Novel approach to support rapid data collection, management, and visualization during the COVID-19 outbreak response in the world Health organization African region: development of a data Summarization and visualization tool. JMIR Public Health Surveill 2020;6:e20355.

$45 \mathrm{CDC}$ Global Health. Global health security agenda: action packages [Internet], 2019. Available: https://www.cdc.gov/globalhealth/ security/actionpackages/real-time_surveillance.htm [Accessed 31 May 2021].

46 South Africa Department of Justice. Protection of personal information act, 2013

47 Aarons GA, Hurlburt M, Horwitz SM. Advancing a conceptual model of evidence-based practice implementation in public service sectors. Adm Policy Ment Health 2011;38:4-23.

48 Sondaal SFV, Browne JL, Amoakoh-Coleman M, et al. Assessing the effect of $\mathrm{mHealth}$ interventions in improving maternal and neonatal care in low- and middle-income countries: a systematic review. PLoS One 2016;11:e0154664.

49 Brinkel J, Krämer A, Krumkamp R, et al. Mobile phone-based mHealth approaches for public health surveillance in sub-Saharan Africa: a systematic review. Int J Environ Res Public Health 2014;11:11559-82.

50 Budd J, Miller BS, Manning EM, et al. Digital technologies in the public-health response to COVID-19. Nat Med 2020;26:1183-92.

51 Human Rights Watch. Africa: Covid-19 Exposes Healthcare Shortfalls [Internet], 2020. Available: https://www.hrw.org/news/ 2020/06/08/africa-covid-19-exposes-healthcare-shortfalls [Accessed 21 Nov 2020].

52 Govindan A. Financing Africa's Healthcare |GBCHealth [Internet] Available: http://gbchealth.org/financing-africas-healthcare/ [Accessed 31 May 2021].

53 Atkinson S, Ingham J, Cheshire M, et al. Defining quality and quality improvement. Clin Med 2010;10:537-9.

54 Rull M, Kickbusch I, Lauer H. Policy debate | international responses to global epidemics: Ebola and beyond. Poldev 2015;6.

55 Campos DP. The Stages of Building Public-Private Partnerships. pdf [Internet], 2015. Available: https://tspace.library.utoronto.ca/ bitstream/1807/69264/1/De_Pinho_Campos_Katia_201506_PhD thesis.pdf [Accessed 01 Jul 2020].

56 Hellowell M. Are public-private partnerships the future of healthcare delivery in sub-Saharan Africa? lessons from Lesotho. BMJ Glob Health 2019;4:e001217.

57 African Development Bank Group. WITS-AfDB Publication. pdf [Internet], 2017. Available: https://www.afdb.org/fileadmin/ uploads/afdb/Documents/Publications/WITS-AfDB_Publication.pdf [Accessed 31 May 2021].

58 Barasa E, Kazungu J, Nguhiu P, et al. Examining the level and inequality in health insurance coverage in 36 sub-Saharan African countries. BMJ Glob Health 2021;6:e004712. 